\title{
Effect of inspiratory muscle-loaded exercise training on peak oxygen uptake and ventilatory response during incremental exercise under normoxia and hypoxia
}

Takeshi Ogawa ( $\nabla$ ogawat@cc.osaka-kyoiku.ac.jp )

Osaka Kyoiku University https://orcid.org/0000-0002-5951-2567

Maiko Nagao

Department of Physical Education, Osaka Kyoiku University

Naoto Fujii

Faculty of Health and Sport Science in University of Tsukuba

Takeshi Nlshiyasu

Faculty of Health and Sport Science in University of Tsukuba

Research article

Keywords: hypoxia, inspiratory muscle training, ventilation, V02peak

Posted Date: February 19th, 2020

DOI: https://doi.org/10.21203/rs.2.15687/v3

License: (c) (i) This work is licensed under a Creative Commons Attribution 4.0 International License. Read Full License

Version of Record: A version of this preprint was published at BMC Sports Science, Medicine and Rehabilitation on April 15th, 2020. See the published version at https://doi.org/10.1186/s13102-02000172-1. 


\section{Abstract}

Background: Although numerous studies have reported the effect of inspiratory muscle training for improving exercise performance, the outcome of whether exercise performance is improved by inspiratory muscle training is controversial. Therefore, this study investigated the influence of inspiratory muscleloaded exercise training (IMLET) on peak oxygen uptake $\left(V_{2 \text { peak }}\right)$, respiratory responses, and exercise performance under normoxic $(\mathrm{N})$ and hypoxic $(\mathrm{H})$ exercise conditions. We hypothesised that IMLET enhances respiratory muscle strength and improves respiratory response, thereby improving $\mathrm{VO}_{2 \text { peak }}$ and work capacity under $\mathrm{H}$ condition.

Methods: Sixteen university track runners ( 13 men and 3 women) were randomly assigned to the IMLET $(n=8)$ or exercise training (ET) group $(n=8)$. All subjects underwent 4 weeks of 20 -min $60 \% V_{2} O_{2 \text { peak }}$ cycling exercise training, thrice per week. IMLET loaded $50 \%$ of maximal inspiratory pressure during exercise. At pre- and post-training periods, subjects performed exhaustive incremental cycling under normoxic $(\mathrm{N} ; 20.9$ $\pm 0 \%)$ and hypoxic $(\mathrm{H} ; 15.0 \pm 0.1 \%)$ conditions.

Results: Although maximal inspiratory pressure (PImax) significantly increased after training in both groups, the extent of PImax increase was significantly higher in the IMLET group (from $102 \pm 20$ to $145 \pm$ $26 \mathrm{cmH}_{2} \mathrm{O}$ in IMLET; from $111 \pm 23$ to $127 \pm 23 \mathrm{cmH}_{2} \mathrm{O}$ in ET; $\left.P<0.05\right)$. In both groups, $V_{2 \text { peak }}$ and maximal work load $\left(\mathrm{W}_{\text {max }}\right)$ similarly increased both under $\mathrm{N}$ and $\mathrm{H}$ conditions after training $(P<0.05)$. Further, the extent of $\mathrm{W}_{\max }$ decrease under $\mathrm{H}$ condition was lower in the IMLET group at post-training test than at pre-training (from $-14.7 \pm 2.2 \%$ to $-12.5 \pm 1.7 \% ; P<0.05$ ). Maximal minute ventilation in both $\mathrm{N}$ and $\mathrm{H}$ conditions increased after training than in the pre-training period.

Conclusions: Our IMLET enhanced the respiratory muscle strength, and the decrease in work capacity under hypoxia was reduced regardless of the increase in $\mathrm{VO}_{2 \text { peak }}$.

\section{Background}

There are some difficulties in attaining success in hypoxic training for improving sea-level competitive performance among athletes; this is related to the lack of sufficient absolute training intensity caused by a substantial decrease in aerobic capacity (1). In the acute hypoxic $(\mathrm{H})$ condition, peak oxygen consumption $\left(\mathrm{VO}_{2 \text { peak }}\right)$ is reduced by impaired gas exchange due to a reduction in the ambient partial $\mathrm{O}_{2}$ pressure. The effect of hypoxia $(2,400-3,000 \mathrm{~m})$ on $\mathrm{VO}_{2 \text { peak }}(2,3)$ is more pronounced in subjects with higher $\mathrm{VO}_{2 \text { peak }}$ with large decrease in haemoglobin $\mathrm{O}_{2}$ saturation $\left(\mathrm{SaO}_{2}\right)$. Notably, individuals with a large increase in maximal minute ventilation $\left(V_{E \max }\right)$ under acute $\mathrm{H}$ condition, relative to those under normoxic $(\mathrm{N})$ condition, show a smaller reduction in $\mathrm{VO}_{2 \text { peak }}(4,5)$, suggesting that a high $V_{\mathrm{E}}$ under $\mathrm{H}$ condition is beneficial for minimising the reduction in $\mathrm{VO}_{2 \text { peak }}$. However, high $V_{\mathrm{E}}$ under $\mathrm{H}$ condition leads to higher $\mathrm{O}_{2}$ cost in the respiratory muscles than that under $\mathrm{N}$ condition (6). Since respiratory muscle work during heavy exercise accounts for $10 \%-15 \%$ of the whole body $\mathrm{VO}_{2}(7)$ even under $\mathrm{N}$ condition, a compromised blood flow to the active muscle during heavy exercise was observed $(8,9)$. Further, diaphragm fatigue has been 
observed following strenuous exercise $(10,11)$, which limits exercise performance $(12,13)$. In this regard, under $\mathrm{H}$ condition, an increase in $V_{\mathrm{E}}$ with a minimum increase in respiratory muscle work may be essential to prevent a greater reduction in the $\mathrm{VO}_{2 \text { peak }}$ and exercise performance under $\mathrm{H}$ condition.

Inspiratory muscle training (IMT) has confirmed the improvement of respiratory muscle strength as a consequence of an increased cross-sectional area (14) in the diaphragm, thereby reducing respiratory muscle fatigue and dyspnoea after an exhaustive exercise $(15,16)$. Some studies reported that IMT improved exercise performance without any change in $V_{O_{2 p e a k}}(17,18)$. However, numerous studies have reported the effect of IMT by attempting to improve exercise performance (19-24), and the outcome of whether exercise performance is improved by IMT is controversial. The discrepancy in the outcomes of IMT would be influenced by study design, training protocol, subject fitness level, and type of exercise test. With regard to training protocol, since IMT is often conducted at a resting condition as well as during exercise, pulmonary ventilation is not high. Indeed, isocapnic hyperventilatory training was reported to improve exercise performance $(25,26)$. Thus, it is postulated that applying inspiratory load during exercise with hyperventilation could have more effect on improving $\mathrm{VO}_{2 \text { peak }}$ and work capacity. In fact, McEntire et al. (27) reported that $15 \%$ PImax inspiratory load-added exercise training greatly improves inspiratory muscle strength and exercise tolerance compared with exercise training alone.

With regard to the effect of IMT on hypoxic exercise, Esposito et al. (28) reported that 8 weeks of IMT did not enhance $\mathrm{VO}_{2 \text { peak }}$ and work capacity under hypoxia $\left(11 \% \mathrm{O}_{2}\right)$. Further, Downey et al. (15) reported that exercise tolerance of $85 \% \mathrm{VO}_{2 \text { peak }}$ constant treadmill running did not change after 4 weeks of IMT. Since the importance of ventilatory response is more emphasised in gas exchange under $\mathrm{H}$ condition than under $\mathrm{N}$ condition, it remains a possibility that inspiratory muscle-loaded exercise training (IMLET) can improve $\mathrm{VO}_{2 \text { peak }}$ and work capacity to a greater extent in $\mathrm{H}$ condition than in $\mathrm{N}$ condition. Therefore, this study aimed to investigate the influence of IMLET on $\mathrm{VO}_{2 \text { peak, }}$, respiratory responses, and exercise performance under $\mathrm{N}$ and $\mathrm{H}$ exercise conditions. We hypothesised that IMLET enhances respiratory muscle strength and improves respiratory response and therefor $\mathrm{VO}_{2 \text { peak }}$ and work capacity under $\mathrm{H}$ condition.

\section{Methods}

\section{Subjects}

Sixteen healthy young volunteers who belong to the university track club (13 men and three women) were recruited for this study. Ten were middle and long-distance runners, and six were sprinters. All subjects did not have any cardiac, pulmonary, and musculoskeletal disease. Subjects were asked to maintain their current diet and regular physical training during the study period. All subjects were instructed to hold similar daily training. Before each testing day, subjects were instructed to avoid vigorous exercise and intake of alcohol and caffeine within $24 \mathrm{~h}$. They were randomly divided into the IMLET group ( 7 men and 1 woman; age, $19.6 \pm 0.9$ years; height; $1.71 \pm 0.09 \mathrm{~m}$; body mass, $57.4 \pm 4.9 \mathrm{~kg}$ ) and exercise training (ET) alone group ( 6 men and 2 women; age, $19.5 \pm 1.4$ years; height; $1.68 \pm 0.06 \mathrm{~m}$; body mass, $54.5 \pm 4.9 \mathrm{~kg}$ ). 
The influence of the menstrual cycle could not be excluded in women; thus, pre- and post-exercise tests were performed at the follicular stage.

This study was approved by the Human Subjects Committees of the Osaka Kyoiku University in accordance with the guidelines set forth by the Declaration of Helsinki. All subjects provided verbal and written informed consent before participating in this study.

\section{Experimental design}

Figure 1 presents the experimental design. Initially, subjects were instructed to familiarise themselves to the test protocols and training protocol. As pre-training period tests, all subjects performed the pulmonary function test and respiratory strength test under $\mathrm{N}$ condition. Incremental cycling tests (see below for details) were performed under $\mathrm{N}(20.9 \pm 0.0 \%)$ and $\mathrm{H}(15.0 \pm 0.1 \%)$ conditions for 1 week. Incremental cycling tests were separately performed in random order with at least 48-h intervals. After the baseline test, all subjects completed 4 weeks of training. Exercise training was conducted 3 days per week for a total of 12 sessions. Since subjects conducted athletic training five times per week, IMLET and ET sessions were held at three times per week. After the training period, subjects performed the same tests as those at baseline (post-training tests).

\section{Exhaustive incremental exercise test}

All subjects performed incremental cycling tests until exhaustion in our laboratory (placed at $132 \mathrm{~m}$ above sea level) under $\mathrm{N}$ and $\mathrm{H}$ conditions. The room temperature was $20.2 \pm 0.4^{\circ} \mathrm{C}$, and the room was continuously ventilated to minimise increases in $\mathrm{CO}_{2}$ concentration in the air. Under $\mathrm{H}$ condition, hypoxic gas was generated by adding moistened $\mathrm{N}_{2}$ gas to ambient air from packed large Douglas bags (700 L). Under both conditions, inspiratory gas was supplied through a pipe from large Douglas bags $(700 \mathrm{~L})$. Subjects breathed through a mouthpiece attached to a pneumotachograph (MLT1000L; AD-Instrument, Sidney, Australia) and a two-way valve (2700; Hands Rudolph, Inc., KS, USA). Subjects started to breathe air 3 min before starting recording of measurements. The incremental cycling test was performed on a cycle ergometer (E-828; Monark, Vansbro, Sweden). Before beginning the exercise, subjects were kept at rest to obtain resting values; subsequently, subjects performed 5 min of warm-up cycling at 30 watts. The pedalling rate was set at $60 \mathrm{rpm}$. The initial pedalling load was set at 60 watts. The pedalling load was subsequently increased by 15 watts every 1 min until exhaustion. The achievement of exhaustion was assumed when the pedalling rate was below $55 \mathrm{rpm}$ despite strong verbal encouragement. Metabolic and ventilatory variables were calculated using the metabolic cart (AE-310s; MINATO Medical; Osaka, Japan). The variables were measured breath-by-breath and calculated at $60 \mathrm{sec}$. All subjects accomplished two of the following three criteria for $V_{2}$ peak: $V O_{2}$ did not increase further despite increases in work load (increase in $<2.0 \mathrm{ml} \mathrm{kg}^{-1} \mathrm{~min}^{-1}$ ) (achieved by $63 \%$ of the subjects), the respiratory quotient was $>1.1$ (achieved by $93 \%$ of the subjects), or the maximal heart rate was $>90 \%$ of the age-predicted value (achieved by $93 \%$ of the subjects). Moreover, all subjects rated 20 on the Borg scale and were exhausted despite strong encouragement. 
To estimate the work of breathing (WOB), oesophageal and mouth pressures were measured using a pressure transducer catheter (MicroSensor Basic Kit: Codman \& Shurtleff, Inc., MA, USA). Airflow was measured using a pneumotachograph (MLT1000L; AD-Instrument; Sidney, Australia). The variables were recorded at a sampling rate of $200 \mathrm{~Hz}$ using Power Lab (Power Lab 8/35; AD-Instrument, Sydney, Australia) and analysis software (LabChart 7; AD-Instrument, Sydney, Australia). Before and after the test measurements, a pressure transducer catheter was carefully calibrated. To obtain calibration signal, a pressure transducer catheter was immersed to $0-60 \mathrm{~cm}$ depth in a darken pipe with water. A pneumotachograph was calibrated by using a $3 \mathrm{~L}$ calibration syringe. An oesophageal pressure catheter was inserted from the nasal passage to a distance $1 / 4$ of the height minus $9 \mathrm{~cm}$ through a nasal cavity and further inserted to the stomach where the oesophageal pressure was confirmed to be changing from negative to positive. Thereafter, the catheter was carefully withdrawn to keep the negative pressure at rest condition (within -1 to $-10 \mathrm{cmH}_{2} \mathrm{O}$ ). The mouth pressure catheter was fixed to the mouthpiece. Transpulmonary pressure was calculated as a difference between the oesophageal pressure and mouth pressure. Since the participants often failed to have inspiratory capacity manoeuvre, lung volume was not estimated during exercise. Thus, the lung volume was reset at the end of the expiration flow. The estimated WOB was calculated as an integration of trans-pulmonary pressure and volume curve. We assessed the tidal volume $(V T)$, respiratory frequency $(f R), V_{E}$, trans-pulmonary pressure, peak expiratory flow rate (PEFR), and WOB every $60 \mathrm{sec}$.

Heart rate was measured using the three-lead electrocardiogram (FE132: AD-Instrument; Sydney, Australia). $\mathrm{SaO}_{2}$ was measured using a forehead pulse oximeter ( $\mathrm{N}-560$; Covidien; CA, USA). Maximal achieved work load $\left(\mathrm{W}_{\mathrm{max}}\right)$ and time to exhaustion were measured to assess the exercise performance.

\section{Pulmonary function and respiratory muscle strength tests}

Pulmonary function and respiratory muscle strength were assessed by spirometry (AS-507, MINATO Medical, Osaka, Japan) according to manufacturer instruction. The subjects familiarised the test protocol before the test day to avoid the learning effect. The vital capacity (VC), forced vital capacity (FVC), and forced expiratory volume in 1 second $\left(\mathrm{FEV}_{1.0}\right)$ were measured in at least three trials. The subjects wore a nose clip and performed the test while standing. The highest value of 3-4 trials was taken as the value for each parameter. The pulmonary function assessment also included the maximal voluntary ventilation performed at $12 \mathrm{sec}$ of maximal ventilatory effort. Respiratory muscle strength was assessed using a handheld mouth pressure meter (AS-507, MINATO Medical, Osaka, Japan).

The respiratory muscle strength was assessed as the static maximal inspiratory and expiratory mouth pressure. All tests were performed in the standing position. Similarly, the subjects familiarised the test protocol before each testing day to avoid the learning effect. The inspiratory muscle strength was evaluated by maximal inspiratory mouth pressure (PImax) measurement. Initially, subjects expired slowly until residual volume (RV) and then performed maximal inspiratory effort from RV. The expiratory muscle strength was evaluated by the maximal expiratory mouth pressure (PEmax) measurement. Initially, subjects inspired slowly until the total inspiratory capacity (IC) and then performed maximal expiratory 
effort from IC. Both PImax and PEmax values were calculated as a mean value of $1 \mathrm{sec}$ including the highest value when maximal pressure was held at least $1.5 \mathrm{sec}$. The values were assigned as the best of at least five satisfactory efforts. Subjects were given verbal encouragement for performing the maximal effort.

\section{Training protocol}

The subjects were assigned to the IMLET group or ET group. At the training day, the IMLET group performed $20 \mathrm{~min}$ of cycling exercise $(60 \mathrm{rpm})$ at $60 \% \mathrm{VO}_{2 \text { peak }}$ of each subject calculated from incremental exercise test under normoxia. The training intensity was determined as the percentage of the intensity of $\mathrm{VO}_{2 \text { peak }}$ observed. Through the exercise, inspiratory pressure was loaded at $50 \%$ PImax by using inspiratory muscle trainer (POWERbreatheK5; IMT Technologies, Birmingham, UK). POWERbreatheK5 requires a predetermined inspiratory pressure throughout the inspiration for opening the electrically controlled shutter, while expiration is not resisted. The subjects were not given any instruction about breathing depth, frequency, or volume during IMLET exercise. Previous studies have reported that a load of the $50 \%$ PImax of IMT elicits an adaptation to the respiratory muscles $(20,22)$. Inspiratory load was calculated from the pre-training period muscle strength test of PImax, and this load was used throughout the IMLET. Meanwhile, the ET group performed 20 min of cycling exercise $(60 \mathrm{rpm})$ at $60 \% \mathrm{VO}_{2 \text { peak }}$ without any resistive inspiratory pressure.

\section{Statistical analysis}

Data are expressed as mean \pm standard deviation. SPSS 25 (IBM, Armonk, NY, USA) was used for all statistical analyses. Variables obtained by respiratory function test were analysed with a specific mixedmodel analysis of variance (ANOVA) with training period variables (pre vs. post-training) and subject groups (IMLET vs. ET). Variables obtained during the incremental exercise test were analysed with threeway repeated-measures ANOVA with factors of the experimental conditions ( $\mathrm{H}$ vs. N), training period, and subject groups. The comparisons of the extent of change by conditions or training period were analysed with two-way repeated-measures ANOVA with the training period variables and subject groups. After detecting the main effect, post-hoc Bonferroni multiple comparisons were performed. Paired t-tests were used to compare the variables of pairwise comparison. The effect size (Cohen's $d(d)$ in the pairwise test

and squared partial eta $\left(\eta_{p}{ }^{2}\right)$ in ANOVA) was calculated when a significant difference was found. $P$ values $<0.05$ were considered statistically significant.

\section{Results}

Participant characteristics are shown in Table 1. No differences in physical and fitness at the pre-training measurement variables were found between the groups. Moreover, no significant differences in age, height, weight, PImax, and $V_{2}$ peak at pre-test were observed between the IMLET and ET groups. 
The results of the pulmonary function test and respiratory muscle strength test are shown in Table 2. Only VC significantly increased by $4.7 \pm 4.2 \%$ after post-training vs at pre-training in the IMLET group $(P<0.05, d$ $=0.48)$. Further, FVC significantly increased in both training groups ( $2.2 \%$ in IMLET and $2.5 \%$ in ET).

The results of the PImax and PEmax are shown in Figure 2 and Table 2. PImax significantly increased after post-training vs pre-training in both the IMLET group $(44.6 \pm 27.3 \% ; P<0.05, d=1.96)$ and ET group (14.9 $\pm 11.8 \% ; P<0.05, d=0.68$ ) (Table 2 and Figure 2). The extent of increase in PImax following training was significantly greater in the IMLET group than in the ET group $(P<0.05, d=1.41$, Figure 2$)$. PEmax significantly increased at post-training vs pre-training in both the IMLET group $(21.6 \pm 25.4 \% ; P<0.05, d=$ $0.82)$ and the ET group $(15.6 \pm 12.1 \% ; P<0.05, d=0.81$ (Table 2 and Figure 2$)$. No difference in the extent of increase of PEmax was found between the IMLET and ET groups.

\section{Incremental exercise test under normoxia}

Table 3 and Figure 3 show the variables of the exhaustive incremental test under $\mathrm{N}$ condition. At posttraining, $\mathrm{VO}_{2 \text { peak }} / \mathrm{w}$ under $\mathrm{N}$ condition increased by $9.2 \pm 7.8 \%$ in the ET group compared with that at pretraining ( $P<0.05, d=0,67$, Figure 3$)$, whereas in the IMLET group, it increased by $11.0 \pm 13.5 \%$, but failed to reach significance $(P=0.058, d=0.97$, Figure 3$)$. The percentage of improvement of $V_{2 \text { peak }} / \mathrm{w}$ by the training was not significantly different between the training groups. $W_{\max }(6.4 \pm 3.7 \%$ in the IMLET; 6.4 $\pm 7.0 \%$ in ET) significantly increased at post-training compared with those at pre-training (Table 3 and Figure 3). $V_{\text {Emax }}$ significantly increased by $16.7 \pm 9.7 \%$ in the IMLET group at post-training vs pre-training $(P<0.05, d=0.82)$. Further, the extent of increase in $V_{E \max }$ at post-training vs pre-training was significantly greater in the IMLET group than in the ET group $(P<0.05)$. No significant difference in WOB was found between before and after training in both training groups. Both Plpeak and PEpeak were not changed by the training in both training groups, while PEFR significantly increased by $20.5 \pm 23.4 \%$ after the training in the IMLET group $(P<0.05, d=0.76)$.

\section{Incremental exercise test under hypoxia}

Table 3 and Figure 3 show the variables of the exhaustive incremental test under $\mathrm{H}$ condition. $\mathrm{VO}_{2 \text { peak }} / \mathrm{w}$ and $\mathrm{W}_{\max }$ were significantly lower in the $\mathrm{H}$ condition than in the $\mathrm{N}$ condition, both at pre- and post-test in all subjects (Figure 3). Especially, the percentage of decrease in $\mathrm{W}_{\max }$ under $\mathrm{H}$ condition $\left(\% \mathrm{dW}_{\max }\right)$ at pre- and post-training tests for the IMLET groups was smaller at post-training than that at pre-training $(-14.7 \pm 2.2 \%$ at pre vs. $-12.5 \pm 1.7 \%$ at post, Figure 4$)(P<0.05, d=1.14)$. All subjects of the IMLET group showed reduced $\% \mathrm{dW}_{\max }$ at post-training compared with that at pre-training. In the ET group, six of eight subjects showed a greater \% dW $\mathrm{max}_{\max }$ at post-training than at pre-training $(-11.7 \pm 6.4 \%$ in pre-test vs. $-12.1 \pm 7.0 \%$ in post-test). $\mathrm{VO}_{2 \text { peak }}$ under $\mathrm{H}$ condition increased after the training period in both groups $(12.9 \pm 13.8 \%$ in the IMLET group, $7.4 \pm 8.8 \%$ in the ET group). The extent of improvement of $\mathrm{VO}_{2 \text { peak }}$ by the training was not significantly different between the training groups. Both maximal $\mathrm{W}_{\max }(9.3 \pm 3.6 \%$ in IMLET, $5.9 \pm 5.2 \%$; $P$ $<0.05)$ and time to exhaustion $(6.2 \pm 4.0 \%$ in IMLET, 39. $\pm 3.4 \%$ in CONT; $P<0.05)$ under $\mathrm{H}$ condition significantly increased after training compared with those at baseline. $V_{\text {Emax }}$ under $\mathrm{H}$ condition was 
significantly higher only in the IMLET group at post-training than at pre-training $(+16.4 \pm 8.2 \% ; P<0.05, d=$ $0.72)$. WOB was increased by $21.9 \pm 21.1 \%$ at post-training than at pre-training in the ET groups $(P=0.05, d$ $=0.84)$. The extent of increase in WOB in the IMLET group was $22.5 \pm 39.5 \%$, but there was no significance $(P=0.18, d=0.71)$. Both Plpeak and PEpeak values were not changed by the training in both training groups, while PEFR significantly increased by $23.9 \pm 31.2 \%$ at post-training in the IMLET group $(P<0.05, d$ $=1.07$ ).

\section{Discussion}

To the best of our knowledge, this study is the first to assess the effect of IMLET on ventilatory response and $\mathrm{VO}_{2 \text { peak }}$ under hypoxia. We hypothesised that IMLET would improve the respiratory response and WOB under $\mathrm{H}$ condition, resulting in improved gas exchange. Thus, we also hypothesised that IMLET could improve $\mathrm{VO}_{2 \text { peak }}$ and work capacity under $\mathrm{H}$ condition. First, although both IMLET and ET enhanced the inspiratory and expiratory muscle strength (Table 2), we found that the magnitude of improvement in inspiratory muscle strength was greater in the IMLET group than in the ET group (Figure 2). Second, under both $\mathrm{N}$ and $\mathrm{H}$ conditions, $\mathrm{VO}_{2 \text { peak }}$ and $\mathrm{W}_{\text {max }}$ increased in both training groups (Figure 3); however, $V_{\mathrm{Emax}}$ increased only in the IMLET group. For exercise under $\mathrm{H}$ condition, although similar changes in $\mathrm{W}_{\max }$ in both training groups were seen, the magnitude of decrease in $\mathrm{W}_{\max }$ under $\mathrm{H}$ condition was significantly smaller in the IMLET groups (Figure 4). Our results suggest that IMLET changes the ventilatory response under $\mathrm{H}$ condition and suppress the extent of decrease in $\mathrm{W}_{\max }$ under $\mathrm{H}$ condition.

\section{Respiratory muscle strength}

Previous studies have reported that 4-10 weeks of respiratory muscle training enhances PImax by approximately $20 \%-30 \%(15,19-21)$. Our IMLET caused a $44 \%$ increase in PImax, suggesting that the respiratory muscle strength improved within a short period. McEntire et al. (27) observed an increase in PImax by $28 \%$ following moderate-intensity exercise training with $15 \%$ PImax inspiratory loads, although PImax also significantly increased by 6 weeks of 30-min cycling exercise training at 70\% peak work rate alone. Compared with that of McEntire et al. (27), we observed an approximately 3-time greater increase in PImax by $50 \%$ PImax inspiratory-loaded exercise training. Both McEntire et al. (27) and the present study observed an improvement of PImax in both the IMLET group and ET group. Some previous studies observed increasing respiratory muscle strength caused by strenuous exercise training itself (29-31). However, we found greater increases in PImax in the IMLET groups than in the ET group, implying that more than $50 \%$ PImax inspiratory load needs to highlight the additional influence of inspiratory load on respiratory muscle strength. Interestingly, PEmax also improved after training in both the IMLET and ET groups. Thus, it is speculated that the increase in PEmax after the training period test is caused by the exercise training per se. More likely, although we did not add expiratory load on the exercise training, the diameter becomes smaller because the subject's mouth is squeezed to hold the inspiratory muscle trainer; thus, slight pressure may have been applied to the expiration. Increasing respiratory muscle endurance was observed in respiratory muscle training, especially with hyperventilatory training $(23,24,26)$, although we did not evaluate the respiratory muscle endurance. 
With regard to exercise performance under $\mathrm{N}$ condition, numerous studies have observed that the exercise performance improved following the respiratory muscle training $(20-22,25,32)$, while others disagreed (15, 24). Since there was no significant difference in the extent of improvement in $W_{\text {max }}$ between the IMLET group and the ET group, the improvement in $\mathrm{W}_{\text {max }}$ caused by the exercise training would not augment, even applying an inspiratory load during the training.

Hyperventilation helps maintain $\mathrm{SaO}_{2}$ during intensive exercise even under normoxia among the subjects with exercise-induced arterial hypoxaemia (33), implying that the gas exchange partly limits the $\mathrm{VO}_{2 \text { peak }}$. Some studies reported that IMT improved exercise performance related to enhanced ventilatory response $(17,18)$. Our result of the increasing $V_{E m a x}$ under normoxia following IMLET is consistent with those of previous studies $(24,27,34)$. However, this increase in $V_{E m a x}$ by IMLET did not contribute to the improvement of $\mathrm{SaO}_{2}$ and $\mathrm{VO}_{2 \text { peak }}$, hence the exercise performance, because our subjects did not express arterial desaturation during maximal exercise. For instance, under $\mathrm{N}$ condition, $\mathrm{VO}_{2 \text { peak }}$ did not change even if subjects were breathing helium $-\mathrm{O}_{2}$ mixtures with lowered air flow resistances (35).

\section{Effect of IMLET on hypoxic exercise}

Esposito et al. (28) reported that $V_{\text {Emax }}$ under $\mathrm{H}$ condition $\left(11 \% \mathrm{O}_{2}\right)$ was increased following IMT compared with pre-training test, which is in agreement with our results. On the contrary, Downey et al. (15) reported that $V_{\mathrm{E}}$ under $\mathrm{H}$ condition $\left(14 \% \mathrm{O}_{2}\right)$ during $~ 85 \% V_{\text {O2peak }}$ submaximal running was reduced following IMT. This disagreement of response in $V_{E}$ following IMT might be due to a difference in test exercise intensity (maximal vs. submaximal). We observed that $V_{\mathrm{E}}$ was not significantly different between pre- and postexercise tests when compared with the same absolute work load (at $W_{\text {max }}$ in pre-test) (not shown in the results; $104.8 \pm 22.0 \mathrm{~L} \mathrm{~min}^{-1}$ in pre vs. $100.5 \pm 26.6 \mathrm{~L} \mathrm{~min}^{-1}$ in post; IMLET group). With this, we can speculate that an increase in $V_{\text {Emax }}$ after IMLET was a result of an increase in work load after IMLET.

A high $V_{E}$ under $\mathrm{H}$ condition appears to be beneficial for minimising the reduction in $V_{2} \mathrm{O}_{2 \text { peak }}(4,5)$, while WOB and oxygen cost of breathing should be higher with an increase in $V_{E}(6)$ compared with those under $\mathrm{N}$ condition. Further, higher WOB would elicit respiratory muscle fatigue $(36,37)$. Accordingly, we hypothesised that the benefit of IMLET would be emphasised under hypoxic exercise condition rather than under normoxic exercise condition. Previous studies have reported that the IMT did not change the $\mathrm{VO}_{2 \mathrm{peak}}$ under $\mathrm{H}$ condition $(15,28)$. We observed an increase in $\mathrm{VO}_{2 \text { peak }}$ in both training groups following the training period. Similar to the $\mathrm{N}$ condition, we cannot deny that the increase in $\mathrm{VO}_{2 \text { peak }}$ under the $\mathrm{H}$ condition was caused by the exercise training itself. Interestingly, $\mathrm{VO}_{2 \text { peak }}$ increases without any increase in $\mathrm{SaO}_{2}$ in both groups after training, which indicates that the magnitude of increase in $V_{\mathrm{E}}$ after IMLET is inadequate for improving the alveoli gas exchange. Thus, the increase in $\mathrm{VO}_{2 \text { peak }}$ may be the result of exercise training causing circulatory function and peripheral adaptation. In fact, $\% \mathrm{~d} V \mathrm{O}_{2 p e a k}$ under $\mathrm{H}$ 
condition did not change even after IMLET. We should speculate one possibility that increase in $V_{\text {Emax }}$ by IMLET was a result of an increase in exhaustion intensity by the training.

High $V_{E}$ under $\mathrm{H}$ condition leads to higher $\mathrm{O}_{2}$ cost in respiratory muscles with an increase of inspiratory flow resistive work and expiratory flow limitation (36). This would lead to a compromised blood flow to active muscles during heavy exercise $(8,9)$. Recently, we have reported that in exhaustive incremental running, higher $V_{\text {Emax }}$ and exercise performance without any change in $V_{2 \text { peak }}$ under hypobaric normoxic condition (492 $\mathrm{mmHg}$ with $32.2 \% \mathrm{O}_{2}$ gas inhalation) than under normobaric normoxic condition (760 $\mathrm{mmHg}$ ) and estimated respiratory muscle $\mathrm{VO}_{2}$ reduced by $23 \%$ under hypobaric normoxic condition, suggesting that lower air density-related reduction of respiratory load affects exercise performance (38). Further, Downey et al. (15) reported that during $85 \% \mathrm{VO}_{2 \text { peak }}$ running under $\mathrm{H}$ condition $\left(14 \% \mathrm{O}_{2}\right), \mathrm{VO}_{2}$ and cardiac output reduced after IMT. In line with this, we hypothesised that if IMLET reduced WOB against hyperventilation, the reduction in exercise performance under $\mathrm{H}$ condition would be attenuated. Our results that $\% \mathrm{dW}_{\max }$ was significantly smaller after training in the IMLET group partly supports the hypothesis that IMLET increased oxygen transport, such as increased blood flow to active muscles. Further, our result of an increase in $V_{E \max }$ without any significant increase in WOB under $\mathrm{H}$ condition following IMLET, not seen in the ET group, implies that the participants can more hyperventilate with similar ventilatory effort after IMLET. Indeed, PEFR and VT at post-training test were higher than those at pre-training test, implying that breathing pattern is altered and increased with elastic work (i.e., recoiled energy work by chest wall inflation). However, we must emphasise the fact that WOB increased by $16 \%$ after IMLET. It is suspected that reduced $\% \mathrm{dW}_{\max }$ after IMLET is a result of reduced limb muscle fatigue due to unloading at submaximal intensity; eventually, the distribution of blood flow in the whole body $\mathrm{VO}_{2}$ at maximal intensity was not different before and after training. Further investigation is warranted to clarify this point.

\section{Limitations}

This study has some limitations. Firstly, we did not fully record subject's daily workout habits. However, subjects were instructed not to change their usual daily activities and not to participate in strenuous exercises. In addition, subjects belonged to the university track club, and similar exercise training was performed in both the IMLET group and ET group, except that in the laboratory. Secondly, subject's fitness level and daily sports modality could have influenced our results. Further, the subjects with highest aerobic power tend to express the greatest decrease in $\mathrm{VO}_{2 \text { pwak }}$ under $\mathrm{H}$ condition (5). When dividing the subject's groups, we ensured that the modalities of sports engaged are the same, and no significant difference was found in $\mathrm{VO}_{2 \text { peak }}$ at the pre-training period between the training groups. Thirdly, exercise training was held only for 20 min per day. If the training duration is longer, the outcome between the ET groups and IMLET group may be different. However, the subjects were close to exhaustion by completing 20 min of exercise with the inspiratory load. Thus, subjects of the IMLET group may not be able to exercise further. Finally, the small number of subjects may have biased our conclusion. However, the minimum sample size was calculated from our study (power $=90 \%, a=0.05$ ). The minimum sample sizes were estimated to be $5,9,8$, 
and 8 for PImax, $V_{2 \text { peak }}, V_{\text {Emax }}$ and $\mathrm{W}_{\text {max }}$ under $\mathrm{H}$ condition, respectively. Further, data collection needs to clarify the effect of IMLET on hypoxic exercise.

\section{Conclusions}

Our results suggest that the exercise training with $50 \%$ PImax inspiratory load could improve inspiratory muscle strength and ventilatory response during hypoxic exercise. The extent of $\mathrm{W}_{\max }$ decrease under $\mathrm{H}$ condition was smaller only in the IMLET group. This implies that IMLET can prevent an excessive decline in exercise performance under acute $\mathrm{H}$ conditions.

\section{Declarations}

\section{Ethics approval and consent to participate}

This study was approved by the Human Subjects Committees of the Osaka Kyoiku University in accordance with the guidelines set forth by the Declaration of Helsinki. All subjects provided verbal and written informed consent before participating in this study.

\section{Consent for publication}

\section{Not applicable}

\section{Availability of data and materials}

Not applicable

\section{Competing interests}

The authors declare that they have no competing interests.

\section{Funding}

This study was supported by the JSPS KAKENHI Grant-in-Aid for Scientific Research (C;17K01759), which provided funding for the design of this study, collection, and analysis. It was also supported by Cooperative Research Grant of Advanced Research Initiative for Human High Performance, University of Tsukuba, which provided funding for the interpretation of data and writing of the manuscript.

\section{Authors' contributions}

T.O. and M.N. conceived and designed the experiments. T.O. and M.N. performed the data analysis. T.O. N.F. and T.N. drafted the manuscript. All authors contributed to the data collection and interpreted the experimental results. All authors edited and revised the manuscript and approved the final version of the manuscript.

\section{Acknowledgements}


We wish to thank all volunteer participants in this study.

\section{Abbreviations}

IMLET Inspiratory muscle-loaded exercise training

IMT Inspiratory muscle training

PEmax Maximal expiratory mouth pressure

PEpeak Peak expiratory pressure

$\mathrm{P}_{\mathrm{ET}} \mathrm{CO}_{2}$ End-tidal partial pressure of $\mathrm{CO}_{2}$

$\mathrm{SaO}_{2}$ Arterial oxyhaemoglobin saturation.

$V_{E}$ Minute ventilation

$V_{\text {Emax }}$ Maximal minute ventilation

$\mathrm{VO}_{2}$ Oxygen uptake

$\mathrm{VO}_{\text {2peak }}$ peak oxygen uptake

VT Tidal volume

WOB Work of breathing

$\mathrm{W}_{\max }$ Maximal work load

\section{References}

1. Chapman RF, Stray-Gundersen J, Levine BD. Individual variation in response to altitude training. J Appl physiol. 1998;85:1448-

2. Koistinen P, Takala T, Martikkala V, Leppaluoto J. Aerobic fitness influences the response of maximal oxygen uptake, and lactate threshold in acute hypobaric hypoxia. Int J Sports Med. 1995;16:78-81.

3. Lawler J, Powers SK, Thompson D. Linear relationship between VO2max and VO2max decrement during exposure to acute hypoxia. J Appl Physiol. 1988;64:1486-92.

4. Marconi C, Marzorati M, Grassi B, Basnyat B, Colombini A, Kayser B, et al. Second generation Tibetan lowlanders acclimatize to high altitude more quickly than Caucasians. J Physiol. 2004;556:661-

5. Ogawa T, Hayashi K, Ichnose M, T Nishiyasu T. Relationship between resting ventilatory chemosensitivity and maximal oxygen uptake in moderate hypobaric hypoxia. J Appl Physiol. 2007;103:1221- 
6. Babcock MA, Pegelow DF, McClaran SR, Suman OE, Dempsey JA. Contribution of diaphragmatic power output to exercise-induced diaphragm fatigue. J Appl Physiol. 1995;78:1710-

7. Aaron EA, Seow KC, Johnson BD, Dempsey JA. Oxygen cost of exercise hyperpnea; implications for performance. J Appl Physiol. 1992;72:1818-

8. Harms CA, Babcock MA, McClaran SR, Pegelow DF, Nickele GA, Nelson WB, et al. Respiratory muscle work compromises leg blood flow during maximal exercise. J Appl Physiol. 1997;82:1573-

9. Harms CA, Wetter TJ, McClaran SR, Pegelow DF, Nickele GA, Nelson WB, et al. Effects of respiratory muscle work on cardiac output and its distribution during maximal exercise. J Appl Physiol. 1998;85:609-

10. Babcock MA, Pegelow DF, Johnson BD, Dempsey JA. Aerobic fitness effects on exercise-induced lowfrequency diaphragm fatigue. J Appl Physiol. 1996;81:2156-

11. Gudjonsdottir M, Appendini L, Baderna P, Purro A, Patessio A, Vilianis G, et al. Diaphragm fatigue during exercise at high altitude: the role of hypoxia and workload. Eur Respir J. 2001;17:674-

12. Harms CA, Wetter TJ, St Croix CM, Pegelow DF, Dempsey JA. Effects of respiratory muscle work on exercise performance. J Appl Physiol. 2000;89:131-

13. Dempsey JA, Romer L, Rodman J. Consequences of exercise-induced respiratory muscle work. Res Physiol Neuro. 2006;151:242-

14. Enright SJ, Unnithan VB, Heward C, Withnall L, Davies DH. Effect of high-intensity inspiratory muscle training on lung volumes, diaphragm thickness, and exercise capacity in subjects who are healthy. Phys Ther. 2006;86:345-

15. Downey AE, Chenoweth LM, Townsend DK, Ranum JD, Ferguson CS, Harms CA. Effects of inspiratory muscle training on exercise responses in normoxia and hypoxia. Res Physiol Neuro. 2007;156:137-

16. Romer LM, McConnell AK, Jones DA. Inspiratory muscle fatigue in trained cyclists: effects of inspiratory muscle training. Med Sci Sports Exerc. 2002;34:785-

17. Salazar-Martínez E, Gatterer H, Burtscher M, Naranjo Orellana J, Santalla A. Influence of inspiratory muscle training on ventilatory efficiency and cycling performance in normoxia and hypoxia. Front Physiol. 2017;8:133.

18. Sheel AW. Respiratory muscle training in healthy individuals. Sports Med. 2002;32:567-

19. Romer LM, McConnell AK, Jones DA. Effects of inspiratory muscle training on time-trial performance in trained cyclists. J Sports Sci. 2002;20:547-

20. Williams JS, Wongsathikun J, Boon SM. Inspiratory muscle training fails to improve endurance capacity in athletes. Med Sci Sports Exerc. 2002;34:1194-

21. Volianitis S, McConnell AK, Koutedakis Y, McNaughton LR, Backx K, Jones DA. Inspiratory muscle training improves rowing performance. Med Sci Sports Exerc. 2007;33:803-

22. Holm P, Sattler A, Fregosi RF. Endurance training of respiratory muscles improves cycling performance in fit young cyclists. BMC Physiol. 2004;4-

23. Sonetti DA, Wetter TJ, Pegelow DF. Effects of respiratory muscle training versus placebo on endurance exercise performance. Respir Physiol. 2001;127:185- 
24. Leddy JJ, Limprasertkul A, Patel S. Isocapnic hyperpnea training improves performance in competitive male runners. Eur J Appl Physiol. 2007;99:665-

25. Inbar O, Weiner P, Azgad Y. Specific inspiratory muscle training in well-trained endurance athletes. Med Sci Sports Exerc. 2000;32:1233-

26. McMahon ME, Boutellier U, Smith RM. Hyperpnea training attenuates peripheral chemosensitivity and improves cycling endurance. J Exp Biol. 2002;205:3937-

27. McEntire SJ, Smith JR, Ferguson CS, Brown KR, Kurti SP, Harms CA. The effect of exercise training with an additional inspiratory load on inspiratory muscle fatigue and time-trial performance. Respir Physiol Neur. 2016;230:54-

28. Esposito F, Limonta E, AlbertiG, Veicsteinas A, Ferretti G. Effect of respiratory muscle training on maximum aerobic power in normoxia and hypoxia. Res Physiol Neuro. 2010;170: 268-

29. Dunham C, Harms CA. Effects of high-intensity interval training on pulmonary function. Eur J Appl Physiol. 2012;112:3061-

30. Wells GD, Plyley M, Thomas S, Goodman L, Duffin J. Effects of concurrent inspiratory and expiratory muscle training on respiratory and exercise performance in competitive swimmers. Eur J Appl Physiol. 2005;94:527-

31. Mickleborough TD, Stager JM, Chatham K, Lindley MR, lonescu AA. Pulmonary adaptations to swim and inspiratory muscle training. Eur J Appl Physiol. 2008;103:635.

32. Tong TK, Fu FH, Chung PK, Eston R, Lu K, Quach B, et al. The effect of inspiratory muscle training on high-intensity, intermittent running performance to exhaustion. Appl Physiol Nutr Metab. 2008;33:67181.

33. Harms CA, Stager JM. Low chemoresponsiveness and inadequate hyperventilation contribute to exercise-induced hypoxemia. J Appl Physiol. 1995;79:575-

34. Markov G, Spengler CM, Knopfli-Lenzin C, Stuessi C, Boutellier U. Respiratory muscle training increases cycling endurance without affecting cardiovascular responses to exercise. Eur J Appl Physiol. 2001;85:233-

35. Esposito F, Ferretti G. The effects of breathing He-O2 mixtures on maximal oxygen consumption in normoxic and hypoxic men. J Physiol. 1997;503:215-22.

36. Babcock MA, Johnson BD, Pegelow DF, Suman OE, Griffin D, Dempsey JA. Hypoxic effects on exerciseinduced diaphragmatic fatigue in normal healthy humans. J Appl Physiol 1995;78:82-

37. Gudjonsdottir M, Appendini L, Baderna P, Purro A, Patessio A, Vilianis G, et al. Diaphragm fatigue during exercise at high altitude: the role of hypoxia and workload. Eur Respir J. 2001;17:674-

38. Ogawa T, Fujii N, Kurimoto Y, Nishiyasu T. Effect of hypobaria on maximal ventilation, oxygen uptake, and exercise performance during running under hypobaric normoxic conditions. Physiol Rep. 2019;7:e14002.

\section{Tables}


Table 1: Variables of the characteristics of subjects

$\begin{array}{llll}\text { IMLET }(\mathrm{n}=8) & \text { ET }(\mathrm{n}=8) & P \text { value } & \text { Effect size }(\mathrm{d})\end{array}$

\begin{tabular}{lcccc}
\hline \hline Sex [M / W] & $7 / 1$ & $6 / 2$ & & \\
\hline Age [years] & $19.6 \pm 0.9$ & $19.5 \pm 1.4$ & 0.82 & 0.11 \\
Height [cm] & $171.3 \pm 8.9$ & $167.5 \pm 5.5$ & 0.31 & 0.59 \\
Weight [kg] & $57.4 \pm 4.9$ & $54.5 \pm 4.9$ & 0.3 & 0.50 \\
PImax [cmH & & & & \\
& $101 \pm 15$ & $104 \pm 22$ & 0.64 & 0.33 \\
$\mathrm{VO}_{2 \text { peak }}\left[\mathrm{ml} \mathrm{kg}^{-1} \mathrm{~min}^{-1}\right]$ & $55.1 \pm 7.2$ & $53.4 \pm 7.7$ & 0.45 & 0.10 \\
\hline
\end{tabular}

Values are mean \pm SD. PImax: maximal inspiratory pressure, $V \mathrm{O}_{2 \text { peak }}$ : peak oxygen consumption

Table 2 Variables of pulmonary function test and respiratory muscle strength test.

\begin{tabular}{|c|c|c|c|c|c|c|c|}
\hline & \multicolumn{2}{|c|}{ IMLET $(\mathrm{n}=8)$} & \multicolumn{2}{|c|}{ ET $(n=8)$} & \multicolumn{3}{|c|}{ ANOVA } \\
\hline & pre & post & pre & Post & period & group & interaction \\
\hline Vital capacity [L] & $\begin{array}{c}4.1 \pm \\
0.4\end{array}$ & $\begin{array}{l}.3 \pm \\
0.5^{*}\end{array}$ & $\begin{array}{c}4.2 \pm \\
0.7\end{array}$ & $\begin{array}{l}4.2 \pm \\
0.7\end{array}$ & $\begin{array}{c}\mathrm{P}=0.14 \\
\eta \mathrm{p}^{2}= \\
0.15\end{array}$ & $\begin{array}{c}\mathrm{P}= \\
0.94 \\
\eta p^{2}= \\
0.00\end{array}$ & $\begin{array}{l}P \mathrm{P}=0.02 \\
\eta \mathrm{p}^{2}=0.34\end{array}$ \\
\hline Force vital capacity [L] & $\begin{array}{c}4.1 \pm \\
0.4\end{array}$ & $\begin{array}{c}4.2 \pm \\
0.5\end{array}$ & $\begin{array}{c}4.0 \pm \\
0.6\end{array}$ & $\begin{array}{c}4.1 \pm \\
0.6\end{array}$ & $\begin{array}{c}\mathrm{P}= \\
0.02 \\
\eta p^{2}= \\
0.34\end{array}$ & $\begin{array}{c}\mathrm{P}= \\
0.81 \\
\eta \mathrm{p}^{2}= \\
0.00\end{array}$ & $\begin{array}{l}\mathrm{P}=0.29 \\
\eta \mathrm{p}^{2}=0.01\end{array}$ \\
\hline $\begin{array}{l}\text { Force expiratory volume in one second } \\
\text { [L] }\end{array}$ & $\begin{array}{c}3.7 \pm \\
0.4\end{array}$ & $\begin{array}{c}3.7 \pm \\
0.3\end{array}$ & $\begin{array}{c}3.7 \pm \\
0.5\end{array}$ & $\begin{array}{l}3.7 \pm \\
0.5\end{array}$ & $\begin{array}{c}\mathrm{P}= \\
0.78 \\
\eta p^{2}= \\
0.06\end{array}$ & $\begin{array}{c}\mathrm{P}= \\
0.76 \\
\eta p^{2}= \\
0.01\end{array}$ & $\begin{array}{c}\mathrm{P}=0.76 \\
\eta \mathrm{p}^{2}=0.01\end{array}$ \\
\hline $\begin{array}{l}\text { Maximal voluntary ventilation by } 12 \\
\text { sec }[\mathrm{L} \mathrm{min}-1]\end{array}$ & $\begin{array}{c}143 \pm \\
31\end{array}$ & $\begin{array}{c}148 \pm \\
33\end{array}$ & $\begin{array}{c}120 \pm \\
35\end{array}$ & $\begin{array}{l}134 \pm \\
26\end{array}$ & $\begin{array}{c}\mathrm{P}=0.07 \\
\eta \mathrm{p}^{2}= \\
0.22\end{array}$ & $\begin{array}{c}\mathrm{P}= \\
0.24 \\
\eta \mathrm{p}^{2}= \\
0.09\end{array}$ & $\begin{array}{l}\mathrm{P}=0.35 \\
\eta \mathrm{p}^{2}=0.06\end{array}$ \\
\hline PImax $\left[\mathrm{cmH}_{2} \mathrm{O}\right]$ & $\begin{array}{c}102 \pm \\
20\end{array}$ & $\begin{array}{l}145 \pm \\
26^{*}\end{array}$ & $\begin{array}{c}111 \pm \\
23\end{array}$ & $\begin{array}{l}127 \pm \\
23 *\end{array}$ & $\begin{array}{c}\mathrm{P}= \\
0.01 \\
\eta \mathrm{p}^{2}= \\
0.54\end{array}$ & $\begin{array}{c}\mathrm{P}= \\
0.51 \\
\eta p^{2}= \\
0.03\end{array}$ & $\begin{array}{c}\mathrm{P}=0.47 \\
\eta \mathrm{p} 2=0.04\end{array}$ \\
\hline PEmax $\left[\mathrm{cmH}_{2} \mathrm{O}\right]$ & $\begin{array}{l}140 \pm \\
29\end{array}$ & $\begin{array}{l}169 \pm \\
29 *\end{array}$ & $\begin{array}{l}135 \pm \\
25\end{array}$ & $\begin{array}{l}155 \pm \\
25 *\end{array}$ & $\begin{array}{c}\mathrm{P}=0.00 \\
\mathrm{np}^{2}= \\
0.73\end{array}$ & $\begin{array}{c}\mathrm{P}= \\
0.58 \\
\eta \mathrm{p}^{2}= \\
0.02\end{array}$ & $\begin{array}{c}\mathrm{P}=0.04 \\
\eta \mathrm{p} 2=0.26\end{array}$ \\
\hline
\end{tabular}


Values are mean $\pm \mathrm{SD} .{ }^{*}$ : significantly different from pre-training, PImax: maximal inspiratory pressure, PEmax: maximal expiratory pressure,

Table 3 Maximal values during incremental test under normoxia and hypoxia 


\begin{tabular}{|c|c|c|c|c|c|c|c|c|c|c|c|c|}
\hline & \multicolumn{4}{|c|}{ Normoxic condition } & \multicolumn{4}{|c|}{ Hypoxic condition } & \multicolumn{4}{|c|}{ ANOVA } \\
\hline & \multicolumn{2}{|c|}{$\operatorname{IMLET}(\mathrm{n}=8)$} & \multicolumn{2}{|c|}{$\operatorname{ET}(n=8)$} & \multicolumn{2}{|c|}{ IMLET $(n=8)$} & \multicolumn{2}{|c|}{ ET $(n=8)$} & \multirow[b]{2}{*}{ condition } & \multirow[b]{2}{*}{ period } & \multirow[b]{2}{*}{ group } & \multirow[b]{2}{*}{ Interaction } \\
\hline & pre & Post & pre & post & pre & post & pre & post & & & & \\
\hline $\begin{array}{c}V \mathrm{O}_{2 \max }[\mathrm{L} \\
\left.\min ^{-1}\right]\end{array}$ & $\begin{array}{l}3159 \\
\pm 464\end{array}$ & $\begin{array}{r}3487 \\
\pm 635\end{array}$ & $\begin{array}{c}2897 \\
\pm 498\end{array}$ & $\begin{array}{l}3171 \\
\pm 489\end{array}$ & $\begin{array}{l}2631 \\
\pm 433\end{array}$ & $\begin{array}{r}2980 \\
\pm 569\end{array}$ & $\begin{array}{r}2546 \\
\pm 424\end{array}$ & $\begin{array}{c}2717 \\
\pm 489\end{array}$ & $\begin{array}{c}\mathrm{P}=0.00 \\
\eta_{\mathrm{p}}^{2}= \\
0.90\end{array}$ & $\begin{array}{c}\mathrm{P}=0.00 \\
\eta_{\mathrm{p}}^{2}=0.55\end{array}$ & $\begin{array}{c}P=0.34 \\
\eta_{p}^{2}=0.07\end{array}$ & $\begin{array}{c}\mathrm{P}=0.35 \\
\eta_{\mathrm{p}}^{2}=0.06\end{array}$ \\
\hline $\begin{array}{l}V \mathrm{CO}_{2 \max } \\
{\left[\mathrm{L} \mathrm{min}^{-1}\right]}\end{array}$ & $\begin{array}{c}3422 \\
\pm 524\end{array}$ & $\begin{array}{l}3752 \\
\pm 584\end{array}$ & $\begin{array}{l}3298 \\
\pm 528\end{array}$ & $\begin{array}{r}3360 \\
\pm 511\end{array}$ & $\begin{array}{l}2924 \\
\pm 383\end{array}$ & $\begin{array}{r}3356 \\
\pm 616\end{array}$ & $\begin{array}{c}2914 \\
\pm \\
479^{\#}\end{array}$ & $\begin{array}{r}3045 \\
\pm 511\end{array}$ & $\begin{array}{c}\mathrm{P}=0.00 \\
\eta_{\mathrm{p}}^{2}= \\
0.82\end{array}$ & $\begin{array}{c}\mathrm{P}=0.00 \\
\eta_{\mathrm{p}}{ }^{2}=0.62\end{array}$ & $\begin{array}{c}P=0.42 \\
\eta_{p}^{2}=0.05\end{array}$ & $\begin{array}{c}\mathrm{P}=0.82, \\
\eta_{\mathrm{p}}^{2}=0.00\end{array}$ \\
\hline $\begin{array}{c}\text { Wmax } \\
\text { [kp] }\end{array}$ & $\begin{array}{c}4.03 \\
\pm \\
0.51\end{array}$ & $\begin{array}{c}4.28 \\
\pm \\
0.49\end{array}$ & $\begin{array}{l}3.72 \\
\pm \\
0.53\end{array}$ & $\begin{array}{c}3.97 \\
\pm \\
0.54\end{array}$ & $\begin{array}{c}3.44 \\
\pm \\
0.44\end{array}$ & $\begin{array}{c}3.75 \\
\pm \\
0.44\end{array}$ & $\begin{array}{c}3.28 \\
\pm \\
0.53\end{array}$ & $\begin{array}{c}3.47 \pm \\
0.54\end{array}$ & $\begin{array}{c}\mathrm{P}=0.00 \\
\eta_{\mathrm{p}}^{2}= \\
0.80\end{array}$ & $\begin{array}{c}\mathrm{P}= \\
0.00, \eta_{\mathrm{p}}^{2}= \\
0.75\end{array}$ & $\begin{array}{c}P=0.32 \\
\eta_{p}^{2}=0.07\end{array}$ & $\begin{array}{c}\mathrm{P}=0.23 \\
\eta_{\mathrm{p}}^{2}=0.10\end{array}$ \\
\hline $\begin{array}{c}V_{\text {Emax }}[\mathrm{L} \\
\left.\min ^{-1}\right]\end{array}$ & $\begin{array}{c}109.6 \\
\pm \\
20.6\end{array}$ & $\begin{array}{c}127.6 \\
\pm \\
23.1\end{array}$ & $\begin{array}{c}106.2 \\
\pm \\
16.7\end{array}$ & $\begin{array}{c}109.9 \\
\pm \\
19.7\end{array}$ & $\begin{array}{c}104.8 \\
\pm \\
22.0\end{array}$ & $\begin{array}{c}121.8 \\
\pm \\
25.0\end{array}$ & $\begin{array}{c}103.6 \\
\pm \\
16.4\end{array}$ & $\begin{array}{l}107.5 \\
\pm 19.7\end{array}$ & $\begin{array}{c}\mathrm{P}=0.08 \\
\eta_{\mathrm{p}}^{2}= \\
0.19\end{array}$ & $\begin{array}{c}\mathrm{P}= \\
0.00, \eta_{\mathrm{p}}^{2}= \\
0.70\end{array}$ & $\begin{array}{c}P=0.00 \\
\eta_{p}^{2}=0.97\end{array}$ & $\begin{array}{c}\mathrm{P}=0.05, \\
\eta_{\mathrm{p}}^{2}=0.83\end{array}$ \\
\hline $\begin{array}{c}f_{\mathrm{R}} \text { [breath } \\
\left.\mathrm{min}^{-1}\right]\end{array}$ & $\begin{array}{c}50.9 \\
\pm 9.7\end{array}$ & $\begin{array}{c}53.7 \\
\pm \\
11.7\end{array}$ & $\begin{array}{r}49.2 \\
\pm 8.5\end{array}$ & $\begin{array}{r}48.3 \\
\pm 9.3\end{array}$ & $\begin{array}{c}48.9 \\
\pm \\
12.1\end{array}$ & $\begin{array}{c}50.3 \\
\pm \\
11.8\end{array}$ & $\begin{array}{c}50.4 \\
\pm 8.6\end{array}$ & $\begin{array}{c}47.6 \pm \\
9.3\end{array}$ & $\begin{array}{c}\mathrm{P}=0.27 \\
\eta \mathrm{p}^{2}= \\
0.08\end{array}$ & $\begin{array}{c}\mathrm{P}= \\
0.91, \eta_{\mathrm{p}}^{2}= \\
0.00\end{array}$ & $\begin{array}{c}\mathrm{P}=0.66 \\
\eta_{\mathrm{p}}^{2}=0.01\end{array}$ & $\begin{array}{c}\mathrm{P}=0.89 \\
\eta_{\mathrm{p}}^{2}=0.01\end{array}$ \\
\hline $\mathrm{VT}[\mathrm{L}]$ & $\begin{array}{c}2.47 \\
\pm \\
0.33\end{array}$ & $\begin{array}{c}2.81 \\
\pm \\
0.45\end{array}$ & $\begin{array}{c}2.30 \\
\pm \\
0.38\end{array}$ & $\begin{array}{c}2.42 \\
\pm \\
0.41\end{array}$ & $\begin{array}{c}2.46 \\
\pm \\
0.24\end{array}$ & $\begin{array}{c}2.85 \\
\pm \\
0.44\end{array}$ & $\begin{array}{c}2.27 \\
\pm \\
0.43\end{array}$ & $\begin{array}{c}2.66 \pm \\
0.41\end{array}$ & $\begin{array}{c}\mathrm{P}=0.50 \\
\eta_{\mathrm{p}}^{2}= \\
0.03\end{array}$ & $\begin{array}{c}\mathrm{P}= \\
0.01, \eta_{\mathrm{p}}{ }^{2}= \\
0.63\end{array}$ & $\begin{array}{c}\mathrm{P}= \\
0.51, \eta_{\mathrm{p}}{ }^{2}= \\
0.03\end{array}$ & $\begin{array}{c}\mathrm{P}=0.58, \\
\eta_{\mathrm{p}}^{2}=0.02\end{array}$ \\
\hline $\mathrm{VE} \mathrm{VO}_{2}^{-1}$ & $\begin{array}{l}34.58 \\
\pm 2.6\end{array}$ & $\begin{array}{c}36.63 \\
\pm \\
2.86\end{array}$ & $\begin{array}{c}37.08 \\
\pm \\
5.33\end{array}$ & $\begin{array}{c}34.69 \\
\pm \\
5.04\end{array}$ & $\begin{array}{c}39.61 \\
\pm \\
3.06\end{array}$ & $\begin{array}{c}40.83 \\
\pm \\
3.80\end{array}$ & $\begin{array}{c}40.89 \\
\pm \\
3.58\end{array}$ & $\begin{array}{r}39.80 \\
\pm 5.04\end{array}$ & $\begin{array}{c}\mathrm{P}=0.01 \\
\eta_{\mathrm{p}}^{2}= \\
0.80\end{array}$ & $\begin{array}{c}\mathrm{P}= \\
0.01, \eta_{\mathrm{p}}^{2}= \\
0.93\end{array}$ & $\begin{array}{c}\mathrm{P}= \\
0.89, \eta_{\mathrm{p}}^{2}= \\
0.01\end{array}$ & $\begin{array}{c}\mathrm{P}=0.42, \\
\eta_{\mathrm{p}}{ }^{2}=0.05\end{array}$ \\
\hline $\mathrm{VE} \mathrm{VCO}_{2}^{-1}$ & $\begin{array}{l}31.9 \\
\pm 2.9\end{array}$ & $\begin{array}{r}33.9 \\
\pm 2.2\end{array}$ & $\begin{array}{c}32.4 \\
\pm 3.3\end{array}$ & $\begin{array}{r}32.8 \\
\pm 3.4\end{array}$ & $\begin{array}{l}35.6 \\
\pm 3.7\end{array}$ & $\begin{array}{c}36.2 \\
\pm 2.7\end{array}$ & $\begin{array}{l}35.7 \\
\pm 2.9\end{array}$ & $\begin{array}{c}35.3 \pm \\
3.4\end{array}$ & $\begin{array}{c}\mathrm{P}=0.00 \\
\eta_{\mathrm{p}}^{2}= \\
0.72\end{array}$ & $\begin{array}{c}\mathrm{P}= \\
0.15, \eta_{\mathrm{p}}^{2}= \\
0.14\end{array}$ & $\begin{array}{c}\mathrm{P}= \\
0.79, \eta_{\mathrm{p}}{ }^{2}= \\
0.01\end{array}$ & $\begin{array}{c}\mathrm{P}=0.72 \\
\eta_{\mathrm{p}}^{2}=0.01\end{array}$ \\
\hline $\begin{array}{c}\mathrm{P}_{\mathrm{ET}} \mathrm{CO}_{2} \\
{[\mathrm{mmHg}]}\end{array}$ & $\begin{array}{c}40.9 \\
\pm 2.2\end{array}$ & $\begin{array}{l}37.2 \\
\pm 2.3\end{array}$ & $\begin{array}{r}40.0 \\
\pm 3.7\end{array}$ & $\begin{array}{r}38.7 \\
\pm 3.1\end{array}$ & $\begin{array}{l}36.6 \\
\pm 3.0\end{array}$ & $\begin{array}{r}34.0 \\
\pm 2.1\end{array}$ & $\begin{array}{r}36.4 \\
\pm 2.8\end{array}$ & $\begin{array}{c}35.9 \pm \\
2.9\end{array}$ & $\begin{array}{c}\mathrm{P}=0.00 \\
\eta_{\mathrm{p}}^{2}= \\
0.81\end{array}$ & $\begin{array}{c}\mathrm{P}= \\
0.03, \eta_{\mathrm{p}}^{2}= \\
0.48\end{array}$ & $\begin{array}{c}\mathrm{P}= \\
0.77, \eta_{\mathrm{p}}^{2}= \\
0.01\end{array}$ & $\begin{array}{c}\mathrm{P}=0.68, \\
\eta_{\mathrm{p}}^{2}=0.01\end{array}$ \\
\hline $\begin{array}{l}\text { WOB [J } \\
\left.\min ^{-1}\right]\end{array}$ & $\begin{array}{c}276 \pm \\
87\end{array}$ & $\begin{array}{c}318 \pm \\
98\end{array}$ & $\begin{array}{c}258 \pm \\
66\end{array}$ & $\begin{array}{c}288 \pm \\
97\end{array}$ & $\begin{array}{c}235 \pm \\
59\end{array}$ & $\begin{array}{c}276 \pm \\
85\end{array}$ & $\begin{array}{c}231 \pm \\
64\end{array}$ & $\begin{array}{c}299 \pm \\
97\end{array}$ & $\begin{array}{c}\mathrm{P}=0.80 \\
\eta_{\mathrm{p}}^{2}= \\
0.01\end{array}$ & $\begin{array}{c}\mathrm{P}= \\
0.04, \eta_{\mathrm{p}}^{2}= \\
0.28\end{array}$ & $\begin{array}{c}\mathrm{P}= \\
0.32, \eta_{\mathrm{p}}^{2}= \\
0.08\end{array}$ & $\begin{array}{c}\mathrm{P}=0.53 \\
\eta_{\mathrm{p}}^{2}=0.03\end{array}$ \\
\hline $\begin{array}{l}\text { PEpeak } \\
{\left[\mathrm{cmH}_{2} \mathrm{O}\right]}\end{array}$ & $\begin{array}{c}24.5 \\
\pm \\
11.2\end{array}$ & $\begin{array}{r}23.2 \\
\pm 7.0\end{array}$ & $\begin{array}{c}26.8 \\
\pm 9.6\end{array}$ & $\begin{array}{c}26.4 \\
\pm \\
11.2\end{array}$ & $\begin{array}{c}22.1 \\
\pm \\
6.3^{\#}\end{array}$ & $\begin{array}{c}22.3 \\
\pm \\
12.6\end{array}$ & $\begin{array}{r}21.6 \\
\pm 5.3\end{array}$ & $\begin{array}{c}21.5 \pm \\
11.2\end{array}$ & $\begin{array}{c}\mathrm{P}=0.01 \\
\eta_{\mathrm{p}}^{2}= \\
0.43\end{array}$ & $\begin{array}{c}\mathrm{P}= \\
0.61, \eta_{\mathrm{p}}^{2}= \\
0.02\end{array}$ & $\begin{array}{c}\mathrm{P}=0.93 \\
\eta_{\mathrm{p}}^{2}=0.01\end{array}$ & $\begin{array}{c}\mathrm{P}=0.81 \\
\eta_{\mathrm{p}}^{2}=0.01\end{array}$ \\
\hline $\begin{array}{c}\text { PIpeak } \\
{\left[\mathrm{cmH}_{2} \mathrm{O}\right]}\end{array}$ & $\begin{array}{c}-27.9 \\
\pm \\
22.8\end{array}$ & $\begin{array}{l}-37.9 \\
\pm 9.7\end{array}$ & $\begin{array}{l}-35.6 \\
\pm 5.3\end{array}$ & $\begin{array}{c}-38.2 \\
\pm \\
10.0\end{array}$ & $\begin{array}{l}-33.8 \\
\pm 4.6\end{array}$ & $\begin{array}{l}-32.7 \\
\pm 8.7\end{array}$ & $\begin{array}{l}-34.0 \\
\pm 7.3\end{array}$ & $\begin{array}{l}-39.1 \\
\pm 8.3\end{array}$ & $\begin{array}{c}\mathrm{P}=0.78 \\
\eta_{\mathrm{p}}^{2}= \\
0.01\end{array}$ & $\begin{array}{c}\mathrm{P}= \\
0.06, \eta_{\mathrm{p}}^{2}= \\
0.25\end{array}$ & $\begin{array}{c}\mathrm{P}=0.48 \\
\eta_{\mathrm{p}}{ }^{2}=0.04\end{array}$ & $\begin{array}{c}\mathrm{P}=0.11 \\
\eta_{\mathrm{p}}^{2}=0.19\end{array}$ \\
\hline $\begin{array}{l}\text { PEFR [L } \\
\left.\text { sec }^{-1}\right]\end{array}$ & $\begin{array}{c}6.39 \\
\pm \\
1.56\end{array}$ & $\begin{array}{c}7.54 \\
\pm \\
1.46\end{array}$ & $\begin{array}{c}6.66 \\
\pm \\
1.65\end{array}$ & $\begin{array}{c}6.63 \\
\pm \\
1.39\end{array}$ & $\begin{array}{l}5.81 \\
\pm \\
1.29\end{array}$ & $\begin{array}{c}7.00 \\
\pm \\
1.53\end{array}$ & $\begin{array}{c}5.35 \\
\pm \\
0.51\end{array}$ & $\begin{array}{c}6.54 \pm \\
1.39\end{array}$ & $\begin{array}{c}P=0.02 \\
\eta_{p}^{2}= \\
0.34\end{array}$ & $\begin{array}{c}\mathrm{P}= \\
0.02, \eta_{\mathrm{p}}{ }^{2}= \\
0.36\end{array}$ & $\begin{array}{c}\mathrm{P}=0.49 \\
\eta_{\mathrm{p}}^{2}=0.04\end{array}$ & $\begin{array}{c}P=0.13 \\
\eta_{p}^{2}=0.17\end{array}$ \\
\hline $\begin{array}{c}\mathrm{HR}_{\max } \\
\text { [beat min- } \\
1]\end{array}$ & $\begin{array}{c}185.5 \\
\pm 7\end{array}$ & $\begin{array}{l}187.7 \\
\pm 7.5\end{array}$ & $\begin{array}{c}184.3 \\
\pm \\
10.4\end{array}$ & $\begin{array}{c}184.5 \\
\pm \\
14.4\end{array}$ & $\begin{array}{l}175.1 \\
\pm 9.4\end{array}$ & $\begin{array}{l}178.0 \\
\pm 8.0\end{array}$ & $\begin{array}{c}180.4 \\
\pm \\
11.7\end{array}$ & $\begin{array}{c}181.0 \\
\pm 14.4\end{array}$ & $\begin{array}{c}\mathrm{P}=0.00 \\
\eta_{\mathrm{p}}^{2}= \\
0.61\end{array}$ & $\begin{array}{c}\mathrm{P}= \\
0.32, \eta_{\mathrm{p}}^{2}= \\
0.61\end{array}$ & $\begin{array}{c}\mathrm{P}=0.65 \\
\eta_{\mathrm{p}}{ }^{2}=0.02\end{array}$ & $\begin{array}{c}P=0.66 \\
\eta_{p}^{2}=0.02\end{array}$ \\
\hline $\mathrm{SaO}_{2}[\%]$ & $\begin{array}{c}96 \pm \\
3\end{array}$ & $\begin{array}{c}96 \pm \\
2\end{array}$ & $\begin{array}{c}96 \pm \\
2\end{array}$ & $\begin{array}{c}97 \pm \\
2\end{array}$ & $\begin{array}{c}82 \pm \\
3^{\#}\end{array}$ & $\begin{array}{c}82 \pm \\
4^{\#}\end{array}$ & $\begin{array}{c}83 \pm \\
2^{\#}\end{array}$ & $\begin{array}{c}84 \pm \\
2^{\#}\end{array}$ & $\begin{array}{c}\mathrm{P}=0.00 \\
\eta_{\mathrm{p}}^{2}= \\
0.97\end{array}$ & $\begin{array}{c}\mathrm{P}= \\
0.43, \eta_{\mathrm{p}}{ }^{2}= \\
0.04\end{array}$ & $\begin{array}{c}P=0.53 \\
\eta_{p}^{2}=0.03\end{array}$ & $\begin{array}{c}\mathrm{P}=0.01 \\
\eta_{\mathrm{p}}{ }^{2}=0.91\end{array}$ \\
\hline
\end{tabular}

Values are mean $\pm \mathrm{SD}$. ${ }^{*}$, significantly different from normoxic exercise; $V \mathrm{O}_{2 \max }$, maximal oxygen consumption; $V \mathrm{CO}_{2 \mathrm{max}}$, maximal carbon dioxide elimination; Wmax, maximal work load; $V_{\mathrm{Emax}}$, maximal minute ventilation; $f_{\mathrm{R}}$, respiratory frequency; VT, tidal volume; $\mathrm{P}_{\mathrm{ET}} \mathrm{CO}_{2}$, end-tidal partial pressure of $\mathrm{CO}_{2}$; WOB, work of 
breathing; PEpeak, peak expiratory pressure; PIpeak, peak inspiratory pressure; PEFR, peak expiratory flow rate; $\mathrm{HR}_{\text {max }}$, maximal heart rate; $\mathrm{SaO}_{2}$, arterial oxyhaemoglobin saturation.

\section{Figures}

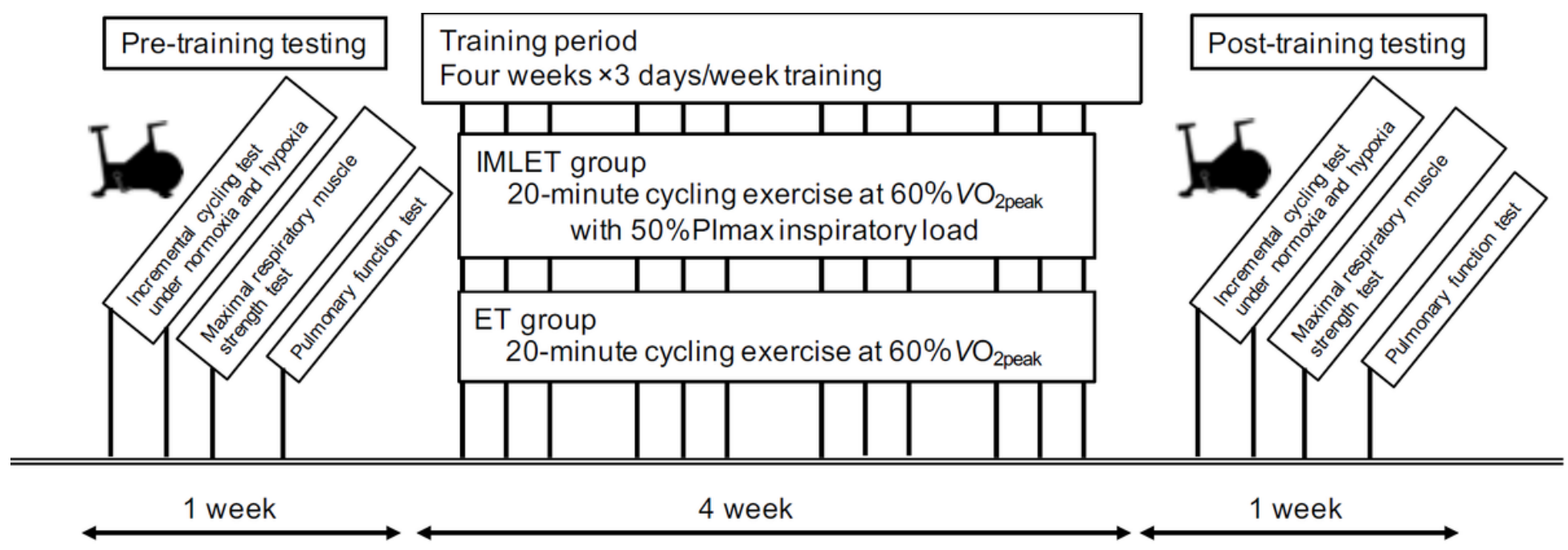

Figure 1

Experimental design. Participants performed the incremental cycling tests under normoxia and hypoxia (15\%02), maximal respiratory muscle strength test, and pulmonary function test within 1 week in the preand post-training period. Participants $(n=16)$ were randomly divided into the inspiratory muscle-loaded exercise training (IMLET, $n=8)$ and exercise training $(E T, n=8)$ groups. Exercise training on a cycle ergometer at $60 \%$ of VO2peak with $50 \%$ of PImax inspiratory muscle-loaded during exercise (IMLET) or at $60 \%$ of VO2peak (ET) for 20 min/day, 3 days/week, for 4 weeks. 


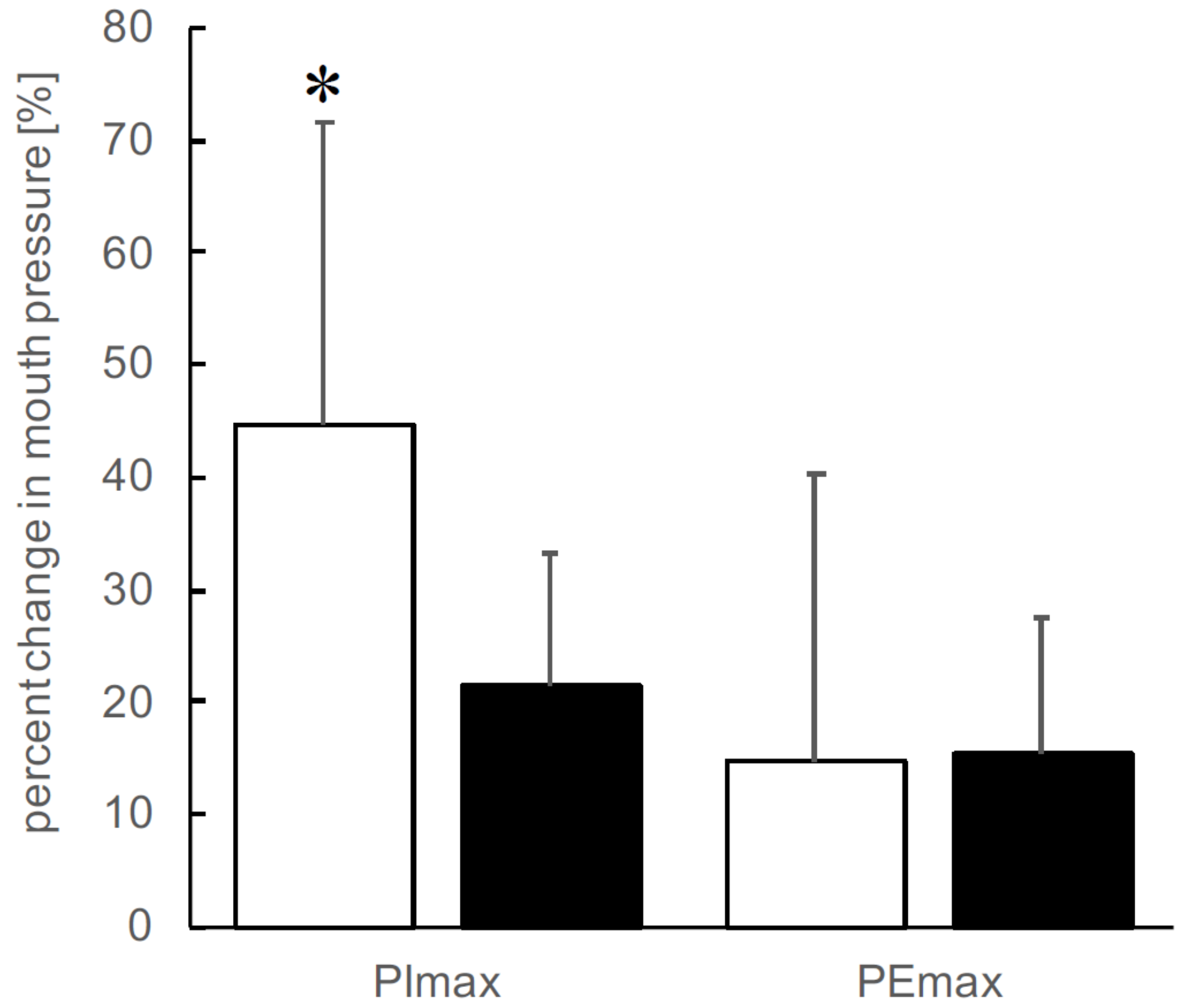

Figure 2

Percentage of change in respiratory muscle strength after the training period. PImax, maximal inspiratory pressure; PEmax, maximal expiratory pressure; white bar represents the inspiratory muscle-loaded exercise training (IMLET) group; black-bar represents the exercise training (ET) group; * $\mathrm{P}<0.05$, IMLET vs. ET. Values are mean \pm SD. 

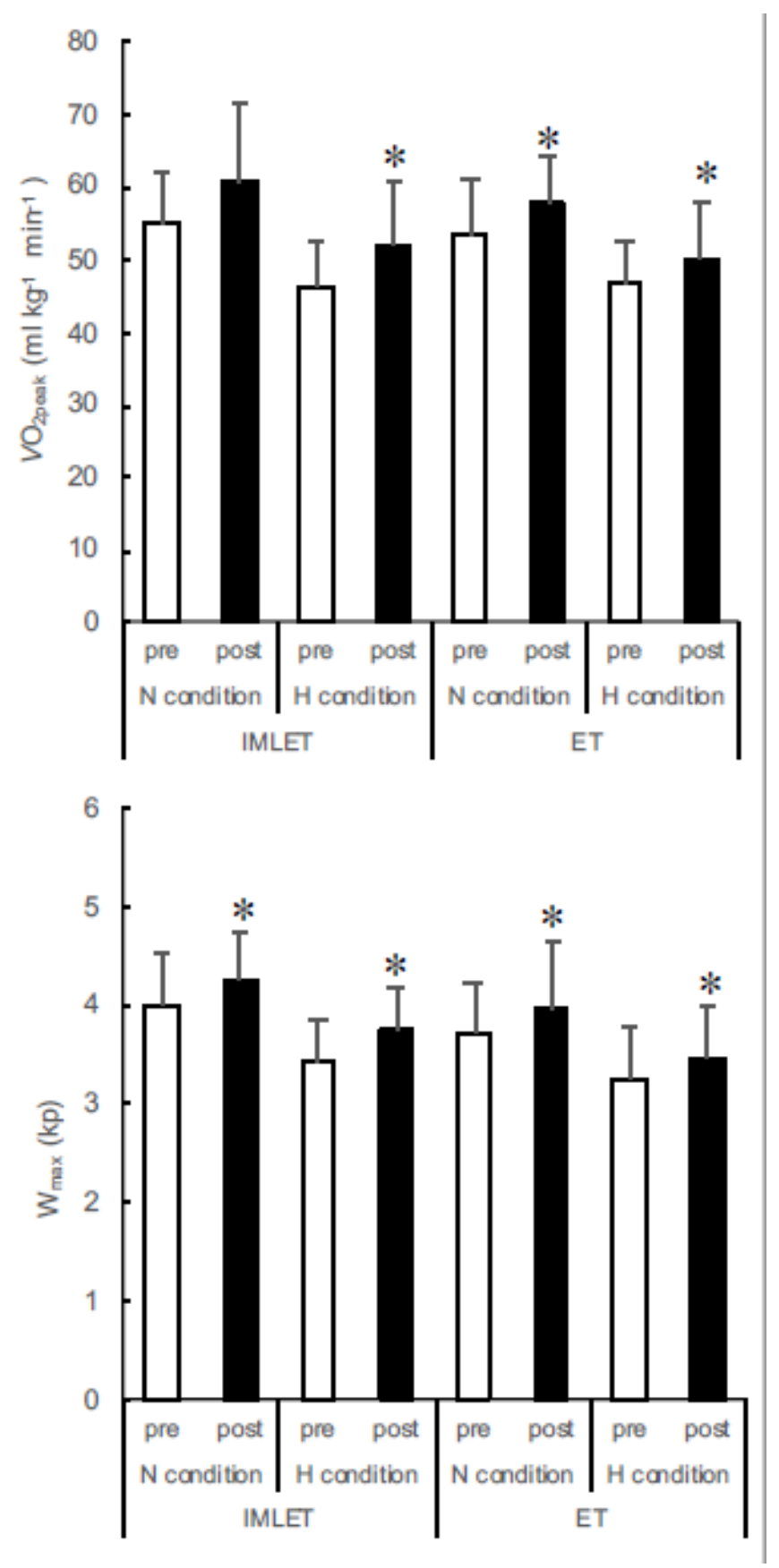

Figure 3

V02peak and Wmax before and after the training period. V02peak, peak oxygen uptake; Wmax, maximal exercise intensity in the incremental exercise test; pre, pre-training period test; post, post-training period test; $\mathrm{N}$, normoxia; $\mathrm{H}$, hypoxia; IMLET, inspiratory muscle-loaded exercise training group; $\mathrm{ET}$, exercise training group; $* 2<0.05$ vs. pre-training test. Values are mean $\pm S D$. 


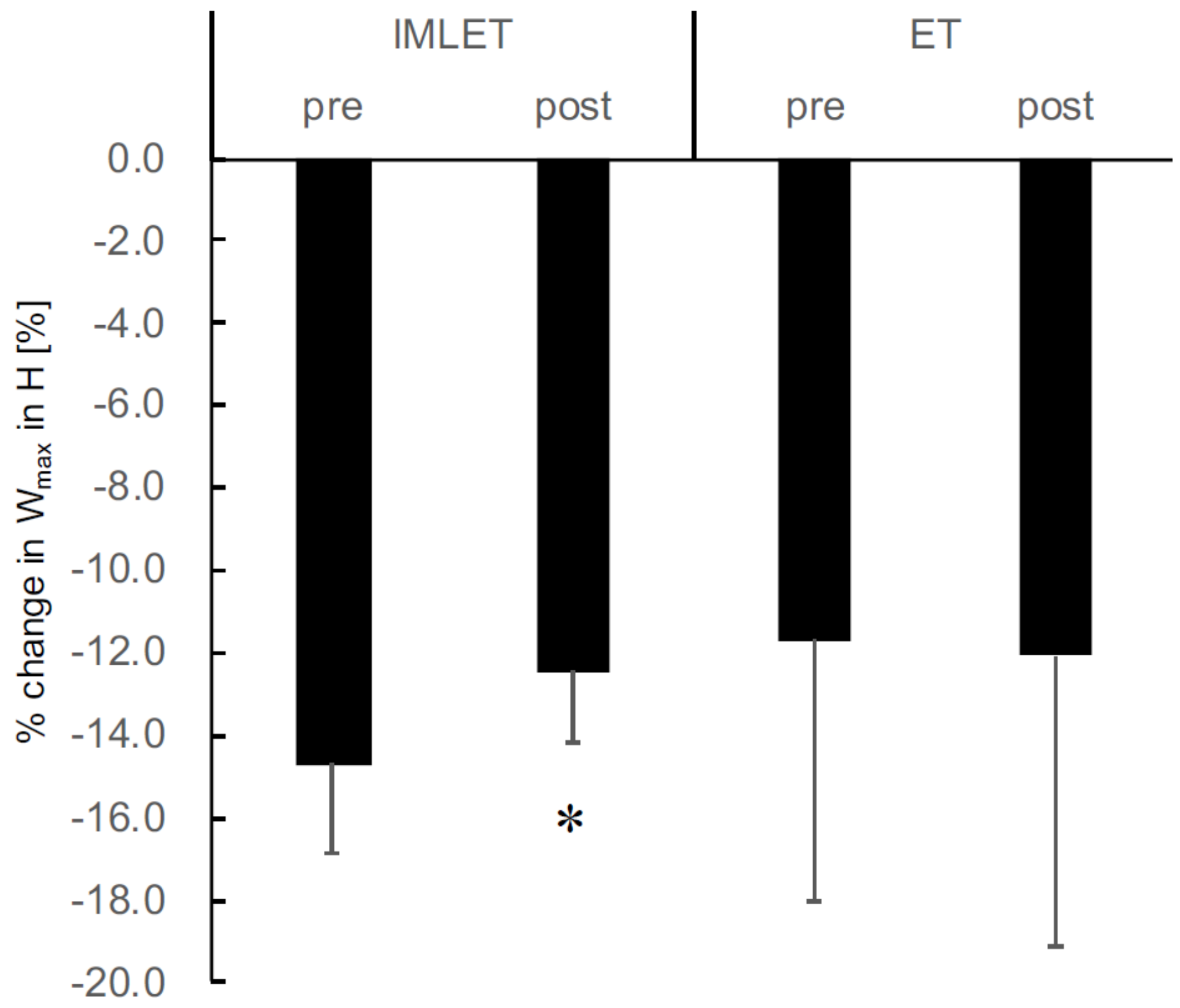

Figure 4

Extent of decrease in Wmax under H condition (\%dWmax) before and after the training period. Wmax, maximal exercise intensity in the incremental exercise test; pre, pre-training period test; post, post-training period test; $\mathrm{H}$, hypoxia; IMLET, inspiratory muscle-loaded exercise training group; $E T$, exercise training group; $* P<0.05$ vs. pre-training test. Values are mean $\pm S D$. 